thodologie..." l. c.). En cualquier caso, parece dificil $y$ desaconsejable el divorcio de ambos aspectos de la confrontación.

77 Vid., especialmente, Drobnig, U., "Methods of Sociological Research in Comparative Law", en RabelsZ, 35 (1971) 496-504. Para elementos de una relación entre Derecho comparado y Sociologia del Derecho, vid. Idem. "Rechtsvergleichung und Rechtssoziologie", en RabelsZ, 18 (1953) 295-309.

78 Señala R. David que utiliza la palabra "funcional", por tratarse de una expresión "à la mode". Vid. "Existe-t-il un droit occidental?", l. c., p. 58

79 Para R. David esa caracteristica esencial que distingue al Derecho occidental es la "rule of law", el ideal según en cual la sociedad debe estar regida totalmente por el Derecho. Idem, Ibid., pp. 59-60.

Esta teoria vio la luz en el trabajo "Zur Lehre von den Rechtskreisen", en XXth Century Comparative and Conflicts Law. Legal essays in hon of llessel Ynteón en Zweigert, K. y Kötz. H., o. c., pp. 63-75.

81 Romanista, alemana, nórdica, del common law, so cialista, asiática. hindú e islámica.

82 Para uma critica concienzuda sobre ambos extremos $c f$. la reseña de David, $R$. Revue international de droit comparé, (1972) 516-519. Preñadas de subjetivismo la mayor parte de las ácidas criticas de Constantinesco, L.-J., o. c., t. III, pp. 127-136 y 155157 , no merecen atención por mor de su inconsistencia.

83 Vid. Constantinesco, L.-J., o. c., t. III, pp. 164 ss., esp. 227-235. Las bases de esta teoria se fundan en su concepción acerca del método comparativo desarrollada en el t. ll de la obra citada.

84 Asi, dentro del sistema continental europeo, el autor diferencia cuatro familias: romanista, latinoamericana, nordica y germanica, y dentro del sistema angloamericano, las familias ding mericana. Idem, Ibid., pp. 84-85.

85 Téngase en cuenta que L.-J. Constantinesco tenia prevista la publicación de un cuarto tomo del Tratado destinado a la clasificación de los sistemas jurídicos, es decil "al objeto de la ciencia de los derechos comparados, pero falleció poco antes de termin in tero. Por esta raton, sus conclusiones bajos, desconociendo cualquier evolución posterior. or.

Aunque, en otro trabajo (The Civil Law Tradition... o. c., pp. 1-5) su autor haya afirmado la existencia demano-canónica y socialista.
romes 7 Merryman, J. H “Modernizaio

Ss.
Idem, Ibid., pp. 80-81.

89 Vid. El concepto de Derecho, trad., Buenos Aires 1963. 90 Merryman, J. H., "Modernizacion...", I. c., pp. 72

$91 \mathrm{Cf}$. Ancel, M., "Le problème de la comparabilité...", l. c., p. 5. Sin embargo, según Zajtay, I., "Réflexi- ons sur l'evolution du droit comparé", en Festsclirift für Konrad Zweigert, Tubinga 1981, pp. 595. $601)$, la clasificación es indispensable y determina el grado de comparabilidad, ;incluso en estudios microcomparativos! La misma idea podia inferirse ya de Idem, "Réflexions sur le problème de la division des familles de droit", en RabelsZ, 37 1973) $210-216$.

92 Zweigert. K., "Méthodologie...", l. c., p. 585.

Idem. Ibid. El autor es tajante: "le comparatiste qui .

95 También parece seguir esta tende. 113. de de los MOZOS, J. L., "Perspectivas...", l. c., que reclama una atención prioritaria del "sistema interno" como objeto del método comparativo.

96 Vid. Villela, A. M., l. c., pp. 119 ss.

97 Vid. de Maekelt, T. B., l. c., pp. 227-228.

Después de revisar escuetamente cómo se configuran los elementos determinantes del Derecho latinoamericano, Villella, A. M., l. c., concluye que juridicamente, pelo menos, a America Latina faz bloco unico com a Europa".

9id. de Maekelt, $T$. B., l.c. una optica eminentemente iusprivatista.

01 De Maekelt, T. B., l. c

102 En contra, Constantinesco, L.-J., o. c., t. III, pp. 19-49 y 75-78, para quien constituye el centro de su argumentación (también en Tratado de Derecho comparado, trad., Madrid 1981, vol. I, pp. 309-317). Sin embargo, como puede observarse a los largo de estas reflexiones, no hemos pretendido, tampoco creemos que proceda, tratar aqui la tantas veces llevada y traida lalsa dialéctica "ciencia de los derechos comparados vs. método comparatifructiferas quente una de las discusiones menos de la Ciencia juridica.

103 Aguilar Navarro, M., Derecho internacional privado, Madrid 1976, vol. I, t. I, p. 70 . Desde hace tiempo se destaca la escasez de resultados prácticos que se obtienen mediante las clasificaciones. 04 En este sentido, vid. Segal, R., Pinto, M. y Colautti, C. E., o. c.

105 Finalidad esencial reconocida a los estudios comparativos

106 Vid. nuestros trabajos citados en nota 1.

Diversos aspectos de esta idea vienen siendo puestos en tela de juicio desde hace algún tiempo. Vid. Strömholm, S., "Rechtsvergleichung und Rechtsangleichung. Teoretische Möglichkeiten und 7. 56 (1992) 611-622. Incluso se ha dicho que referirse a la "armonizacion" del Derecho en el seno de una familia juridica, implica en cierto modo una tautologia ya que "families of law constitute systems which include a harmonization component by definition". Vid. Boodman, M., "The Myth of Harmonization of Laws", en American Journal of Comparalive Law, 39 (1991) 704.

\title{
A Remissão no Direito Tributário Brasileiro
}

\author{
EuRÍPEDES GOMES FAIM FILHO \\ Juiz de Direito no Estado de São Paulo. \\ Ex-professor de Direito da UNESP, ITE e UNOESTE. \\ Membro do IBDT/USP \\ Pós-graduando da Faculdade de Direito \\ do Largo de São Francisco da USP
}

\section{INTRODUÇ̃̃O}

Encontramos pouca literatura juridica sobre o tema remissão tributária a maioria dos livros e tratados apresenta breve estudo sobre o assunto, às vezes resumido a uma única página, por isso entendemos que é necessário discorrer mais sobre este tema dando-lhe um tratamento mais profundo e foi o que tentamos fazer aqui e isto também porque achamos que a remissão tem sido usada como errado instrumento de politica fiscal, como exporemos no texto.

Assim, tentaremos neste trabalho dizer o que se pode entender como sendo remissão, qual sua natureza juridica e requisitos legais, bem como outras observaçōes sobre o assunto, sem ter a pretensão de esgotá-lo.

Por fim, analisaremos um exemplo concreto de lei que tenha concedido este beneficio fiscal para averiguar se os requisitos legais têm ou não sido seguidos.

Desta forma pretendemos dar uma pequena contribuição sobre o assunto que achamos de grande relevância pelos motivos que daremos no decorrer do texto.

\section{CONCEITO DE REMISSÃO}

Pode-se conceituar a remissão como sendo o ato praticado pelo credor que, por liberalidade, desobriga o devedor de quitar a divida.

$J \operatorname{ardim}^{2}$ ensina que a origem etimológica da palavra é a seguinte: re (para trás) + missio (deixar-se levar) = remissio-onis (mandar para trás, abrandamento, suavidade, indulgência e perdão).
Lembra Baleeiro ${ }^{3}$ que não se pode confundir remissão com remição, que antigamente tinha a mesma grafia causando maior confusão do que hoje. Explica ele que remição vem do latim redimere ato de remir, redimir ou resgatar a divida por parte do devedor ou algum interessado 4 .

Já remissão tem sua origem na palavra latina remissio, remissionem, ato de remitir, em outras palavras, perdoar a divida, renúncia do credor ao seu crédito.

Ocorre muita confusão também com 0 instituto da anistia fiscal, o que não deveria acontecer porque esta abrange exclusivamente as infrações cometidas ${ }^{5}$ enquanto que a remissão não trata de infrações, mas sim de débitos fiscais normais.

Ensina, contudo, Denari ${ }^{6}$ que na essência as noçōes de anistia e de remissão estão interligadas, pois ambas estão relacionadas ao perdão de um débito tributário, sendo a anistia espécie de remissão que se aplica às penalidades por infraçōes tributárias.

Tanto no Direito Tributário quanto no Direito Privado a remissão pertence à parte obrigacional e se trata de uma liberalidade do credor, a diferença reside no fato de que neste ela resulta da vontade das partes e naquele ela se origina na lei.

Ressalte-se que como a remissão é um ato de disposição de patrimônio o credor que a realiza necessita possuir capacidade para agir e disponibilidade do bem, o que se aplica no Direito Tributário onde apenas 0 ente com capacidade de instituir o imposto pode perdoá-lo.

Por fim, não se olvide que no Direito Privado o instituto da remissão não se confunde com a 
renúncia porque 0 devedor beneficiado por aquela pode não aceitá-la e consignar em pagamento e já no Direito Tributário tal faculdade não existe por ser a remissão "ex lege", caracterizando-se assim verdadeira renúncia do Fisco.

Conceituada a remissão e desfeita a confusão com outros institutos passa-se a questionar sua natureza juridica.

\section{NATUREZA JURÍDICA DA REMISSÃo}

A natureza juridica da remissão tributária não está pacificada existindo diversas teorias a respeito do assunto.

Para ver qual delas melhor se adequa ao caso nos socorreremos de conceitos do Direito Privado que, como ensinou Costa ${ }^{7}$, podem e devem ser usados no Direito Tributário, em tudo o que não houver conflito e no que couber.

Há três posições básicas sobre o tema:

1. Para alguns a lei cancela débitos fiscais sem atividade nenhuma da autoridade adminis trativa ou do contribuinte, portanto trata-se de um ato legislativo unilateral. $A$ lei deve ser respeitada pelo Fisco, que não pode cobrar, e pelo peitada pelo Fisco, que não pode cobrar, e pelo
contribuinte, que não pode pagar, mesmo quecontribuinte, que não pode pagar, mesmo que-
rendo.

2. Para outros a lei autoriza a autoridade fiscal a conceder remissão, atendidas certas exitribuinte perante o Fisco, que assim demonstra seu desejo de obter a remissão. O Fisco analisa o cumprimento das exigências legais, e estando o cumprimento das exigências legais, e estando
estas satisfeitas, deve ele conceder a remissão, estas satisfeitas, deve ele conceder a remissão,
não podendo deixar de fazê-lo. Assim só o connão podendo deixar de fazē-lo. Assim só o contribuinte expressa sua vontade, sendo irrelevante partir de um negócio juridico unilateral do devedor.

3. Por fim, há aqueles que entendem que na hipótese da remissão concedida com base em considerações de eqüidade relacionadas com os aspectos pessoais ou materiais do caso haveria uma atuação de vontade da autoridade, bem como do contribuinte que pede o beneficio: trata-se assim de um negócio juridico bilateral.

Em que pese doutos entendimentos em contrário entendemos que a atividade administrativa tributária é plenamente vinculada. Assim sendo, deve-se entender a expressão "autorizar" constante no art. 172 do C.T.N. no mesmo sen- tido que se entende a expressão "pode", como quando a lei diz que o juiz pode isto ou aquilo pois na verdade trata-se de um poder-dever, ou seja, estando presentes os requisitos legais configura-se 0 direito do interessado e o dever da autoridade de reconhecê-lo.

Desta forma entendemos não ser possive falar-se em vontade da autoridade, posto que esta é irrelevante em atos vinculados, não classificando assim a remissão como negócio jurídico bilateral em nenhuma hipótese.

Carrazza ${ }^{8}$ é enfático a este respeito dizendo: "A Fazenda Pública não é a 'dona' do tributo. Ela o lança e o arrecada, nos estritos termos da lei. Não lhe é dado abrir mão, 'sponte propria', de seu recolhimento. Pelo contrário, só poderã deixar de arrecadá-lo em cumprimento a uma lei autorizadora (praticará, pois, também neste caso, um ato administrativo vinculado)".

Seria por acaso um negócio juridico unilateral onde basta a vontade de uma das partes, no caso o sujeito passivo? Entendemos que não porque o contribuinte não pode obrigar o Fisco a receber algo que a lei perdoou.

Resta portanto a primeira hipótese que nos parece a mais acertada: a remissão tributária é um ato legislativo unilateral, obrigatório tanto para o Fisco como para o contribuinte.

Definida a natureza juridica da remissão passemos a ver como ela é disciplinada no nosso Direito.

\section{A REMISSÃo NO CÓDIGO TRIBUTÁRIO}

\section{NACIONAL}

O Código Tributário Nacional regula a remissão no seu art. 172.10 Baleeiro afirma que este artigo diz respeito ao mesmo instituto do Direito Civil encontrado nos arts. 1053 a 1055 do CC.

Passaremos a analisar este artigo do C.T.N. com mais detalhes como segue.

\section{HIPÓTESES DE REMISSÃO - TAXATIVAS OU}

\section{EXEMPLIFICATIVAS}

Afirma Jardim que as hipóteses previstas para concessão de remissão não são uma lista taxativa, mas meramente exemplificativa.

Entendemos diversamente deste autor porque a regra é que todos contribuam, no limite de suas posses, para a manutenção do Estado, sendo a remissão uma exceção e como tal não pode ser interpretada extensivamente.

Assim é que ensina França"l dizendo que "todas as leis excepcionais ou especiais devem se interpretadas restritivamente"

Mais especificamente no campo tributário NOGUEIRA ensina que "devemos ter em ment que o Direito Tributário tem por finalidade disciplinar a tributação com o escopo de obter re ceitas para o Estado..."12 (grifo nosso), portanto qualquer coisa que vá contra esta finalidade é excepcional e como exceção deve ser encarada.

Finalizando a questão diz ainda Nogueira: " $A$ interpretação por analogia ou qualquer proces so de preenchimento de lacuna da lei para cobrar tributo ou impor pena tributária, para modificar, dispensar ou extinguir o tributo, quernos parecer impossivel, ilegitima, face à Consti tuição, pois a obrigação tributária é uma 'obligatio ex lege" (grifo nosso) ${ }^{13}$

Moreira alerta que José Geraldo Ataliba Nogueira não concorda com Ruy Barbosa Nogueira dizendo que "não tem cabimento... sustenta a tese da interpretação estrita ou restritiva do direito tributário, a qual resulta da concepção excepcional desse ramo de direito. Concluimos. que a interpretação do direito tributário è a mesma aplicável às demais normas de direito comum ${ }^{14}$."

Diz Moreira que os dois mestres tinham parcial razão, pois um buscava a segurança juridica e o outro objetivava evitar abusos advindos de interpretação muito dura da lei.

Pelas razões expostas no texto acatamos lição de Ruy Barbosa Nogueira porque, embor esta seja anterior ao C.T.N., é ela ainda válida, portanto excecōes só podem ser criadas por Lei.

Jogando uma última pá de cal sobre o assunto temos 0 art. 108, $\S 2^{\circ}$, do C.T.N. que di "O emprego da eqüidade não poderá resultar na dispensa de pagamento de tributo devido."

Respondida esta indagação, passemos a ver uma a uma das cinco hipóteses taxativas de remissão previstas no Código Tributário Nacional no seu artigo 172
SITUAÇÃO ECONÔMICA DO SUJEITO PASSI VO

Baleeiro ensina que esta modalidade de remissão beneficiaria o sujeito passivo sem condições econômicas de saldar sua divida fiscal, não importando o motivo, pois o C.T.N. não exclui nem a culpa deste no caso.

Já Fanucchi diz que esta modalidade ocorre quando o contribuinte não tem como saldar sua obrigação por falta de recursos.

Frente ao disposto no Código tem-se que concordar com os dois mestres, em especial quanto à observação de Baleeiro de que o motivo no caso é irrelevante.

\section{ERRO DE FATO OU IGNORÂNCIA ESCUSÁVEL}

Baleeiro ressalta que 0 erro ou a ignorância têm que ser de fato não se admitindo o erro de direito, porque a ninguém é dado afirmar que não conhece a lei para não respeitá-la. Fanucchi se expressa de maneira idêntica.

\section{CRÉDITO DE DIMINUTO VALOR}

Baleeiro diz que aqui se trata do crédito fiscal de valor insignificante, caso em que fica mais caro cobrá-lo que dispensá-lo, sendo que geralmente esta remissão é feita genericamente pela lei.

Lembra Fanucchi que aqui ocorre muita confusão com a anistia, o que não se justifica como se viu acima.

Bonilha ${ }^{15}$ preparou 0 mais longo estudo que encontramos sobre o assunto onde recorda que esta forma de remissão é objetiva, diversamente das demais hipóteses que dependem da situação subjetiva do contribuinte.

Diz Bonilha que esta modalidade de remissão atende mais aos interesses do Fisco do que dos sujeitos passivos porque ela tem o escopo de evitar um grande número de cobranças de créditos de valor econômico irrisório, o que traz prejuizos para o Erário devido ao fato já mencionado de que exigi-los é mais dispendioso que dispensá-los. 
Bonilha exemplifica com o caso da Lei Fedeal $7450 / 85$ que perdoou dividas fiscais, mas sem que este perdão implicasse "restituição de quantias pagas, nem compensação de dividas" (art. 77). ${ }^{16}$

\section{EQÜIDADE}

Entendemos como Moreira ${ }^{17}$ que afirmou que como o Código menciona a eqüidade é necessário dizer-se do que se trata, em que pese entendimentos contrários à sua aplicação e a opinião de alguns que acham que este conceito é confuso e gerador de discordâncias sem fim, pois a definição do que seja eqüidade gera grande discussão doutrinária desde longa data.

Moreira conceitua eqüidade como sendo "o reconhecimento e propiciação da igualdade material" que tanto pode ser "in mellius" quanto "in pejus".

Conforme Silveira ${ }^{18}$ a eqüidade tem o conceito vulgar de Justiça no caso concreto, sendo tradicionalmente equiparada à Justiça ideal, não à Justiça legal. Ela se faz necessária em alguns (ipos de casos concretos: a) a generalidade exacerbada da lei não satisfaz o caso concreto; b) há omissão da lei quanto ao caso concreto; e c a solução legal não se adequa ao caso concreto total ou parcialmente. Lembra ele que hả doutrinadores que entendem que o juiz pode não aplicar a lei que se mostrar inadequada ao caso concreto.

Fanucchi afirma que às considerações de eqüidade têm por objetivo restaurar a isonomia prejudicada por hipóteses iguais, mas com re sultados tributários diversos

Baleeiro ressalta que as consideraçōes de eqüidade são relacionadas a aspectos personalissimos do contribuinte ou materiais do caso. Cita ele ainda Aristóteles que disse: "A natureza própria da eqüidade consiste em corrigir a lei, na medida em que esta se mostra insuficiente em razão de seu carăter geral" 19

Segue Baleeiro dizendo que não concorda com Pontes de Miranda quando este afirma que a eqüidade nada mais é do que uma permissã legal dada a alguém para decidir com liberdade no caso concreto camuflada pela falta de objetvidade desta expressão, porque tambemo o cor ceito de "principios gerais do Direito" é vago, tendo a doutrina tentado dar limites ao conceito da eqüidade.

Baleeiro diz ainda que a eqüidade presta-se para suprir as lacunas legais, mas também serve para interpretar e adequar a lei que se mostrar injusta no caso concreto devido a seu caráter genérico e impessoal, sendo que pela eqüidade se procura satisfazer a Justiça, cujo conceito depende do momento e latitude em que se vive.

Pelo exposto podemos dizer que se entende eqüidade como sendo à satisfação do sentimento de Justiça ferido pela disposição legal que não se adequa ao caso concreto. No nosso caso, se a disposição legal se mostrar injusta ao ser aplicada, pode ela ser mitigada aplicando-se até a remissão no objetivo maior de atingir a Justi-

Importante ressaltar que, como a atividade tributária é vinculada, a Lei que autorizar a autoridade administrativa a conceder remissão neste caso deve dizer clara e expressamente quais são as "considerações de eqüidade, em relação com as caracteristicas pessoais ou materiais do caso", portanto, no nosso entender as análises referentes a cabimento da eqüidade seriam feitas no âmbito legislativo. ${ }^{20}$

\section{PECULIARIDADES REGIONAIS}

Seriam abrangidas por esta hipótese calamidades públicas, profunda crise econômica, comoção política, endemias, epizootias que dizimem rebanhos, etc

Outro caso lembrado por Fanucchi ocorre quando se concede 0 beneficio a contribuintes de áreas menos desenvolvidas do território.

Conhecendo-se as hipóteses de remissão que há surge a questão de como pode ela ser dada.

\section{FORMA DE CONCESSÃO}

Alguns juristas entendem que a remissão tributária pode ser concedida apenas pela lei, sem necessidade de nenhuma atividade da autoridade administrativa. Para estes existiriam dois casos de concessão de remissão: 1. remissão concedida com necessidade por parte da autoridade administrativa; e 2 . remissão concedida diretamente pela lei, sem ne- cessidade de nenhum ato complementar, salvo os atos internamente necessários.

Fanucchi ao diferenciar a anistia da remissão afirma: "a remissão é extintiva desse mesmo crédito e é concedida quer haja, ou não, infração à legislação por parte do sujeito passivo, porém sempre dependente da concessão individuada de autoridade administrativa." 21 (grifo nosso). Diz ele que a lei deve dizer qual é a autoridade com atribuição para conceder o beneficio, mas, evidentemente, no silêncio da lei, coisa comum de acontecer, deve-se entender que é a mais alta autoridade fazendária ou quem esta designar, sob pena de frustrar-se o direito do contribuinte.

Jardim $^{22}$, por sua vez, afirma que "o conceder remissão implica despacho motivado, no qual o signatário adnumera as razões da renúncia ao crédito tributário" (grifo nosso).

Concordamos com estes dois autores no sentido de que a participação da autoridade administrativa é essencial não podendo se limitar aos atos internamente necessários, mas devendo conceder a remissão por despacho fundamentado.

O proprio teor do art. 172 do C.T.N. ao nosso ver não deixa dúvidas dizendo: "A lei pode autorizar a autoridade administrativa a conceder, por despacho fundamentado, remissão total ou parcial do crédito tributário..." (grifo nosso). Portanto só a lei autoriza e só a autoridade fiscal concede a remissão, sendo necessário o concurso da lei e da autoridade administrativa.

De qualquer forma a autoridade administrativa não pode conceder remissōes de forma discricionária porque a atividade tributária é plenamente vinculada, devendo a remissão sempre vir da lei.

Seria dispensável dizer-se que a recusa imotivada da autoridade administrativa em cumprir a lei que autorizou a remissão poderia ser superada pela autoridade judiciária em mandado $d$ segurança.

\section{REMISSÃO E DIREITO ADQUIRIDO}

O parágrafo único do art. 172 do C.T.N. tem a seguinte redação: "O despacho referido neste artigo não gera direito adquirido, aplicando-se, quando cabivel, o disposto no art. 155."

Por sua vez dispóe 0 artigo 155 do C.T.N.: "A concessão da moratória em caráter individual não gera direito adquirido e será revogada de oficio, sempre que se apure que 0 beneficiado não satisfazia ou deixou de satisfazer as condiçoes ou não cumpria ou deixou de cumprir os requisitos para a concessão do favor cobrandose 0 crédito acrescido de juros de mora: I - com imposição da penalidade cabivel, nos casos de dolo ou simulação do beneficiado, ou de terceiro em beneficio daquele; II - sem imposição de penalidade, nos demais casos. Parágrafo único. No caso do inciso I deste artigo, o tempo decorrido entre a concessão da moratória e sua revocaça näo se computa para efeito da prescrição do direito à cobrança do crédito; no caso do inciso II deste artigo, a revogação só pode ocorrer antes de prescrito o referido direito."

Alguns doutrinadores entendem que, devido a esta determinação legal, o despacho da autoridade administrativa que concede a remissão não gera direito adquirido, sendo ela revogável ex officio sempre que se constatar que o contribuinte não cumpria com as exigências legais para o recebimento do beneficio, executando-se 0 crédito acrescido de juros de mora.

Note-se que a remissão diverge da moratória porque nesta pode-se dizer que o contribuinte parou de satisfazer as exigências legais, pois estas podem se referir ao futuro, já na remissão só se trata de requisitos existentes na época da so se trata de requisitos existentes na epoca da
sua concessão, referindo-se, portanto, ao passado.

Lembram alguns mestres que este parágrafo unico não tem utilidade porque se 0 contribuinte não tivesse satisfeito as exigências legais nunca poderia ter adquirido qualquer direito. Neste caso a concessão da remissão estaria maculada por vicio de ilegalidade e, assim, poderia ser revogada a qualquer momento. Seguem nesta linha, entre outros, Baleeiro e Fanucchi.

Acrescenta Fanucchi que a outorga do benefício não gera direito adquirido podendo ser revogada a qualquer tempo como qualquer outro administrativo voltando o crédito tributário ao que era antes na sua integridade. Assim não 
é correto dizer-se que a remissão sempre extingue o crédito tributário, sendo em alguns casos causa suspensiva apenas. No entanto diz ele que a revogação equivale à da moratória, com os mesmos efeitos.

Critica Jardim o dizer de alguns tributaristas e do C.T.N. de que o despacho que concede a remissão pode ser revogado porque segundo ele este despacho é ato plenamente vinculado e não discricionário, portanto não cabe nele revogação, mas tão somente invalidação (anulação ou reconhecimento de nulidade)

Diz Jardim que “... a remissão efetivada mediante ato legitimo gera direito adquirido, ao contrário do que dispõe o Código e ao reverso do que imprópria e prestamente se pensa" (p. 169)

Estamos com Jardim por entender também como ele que a atividade administrativa tributária é plenamente vinculada e que se o contribuinte satisfaz as exigenncias da lei tem ele sim direito adquirido, pois caso contrário não seria próprio dizer sequer que este tenha tido direito à remissão concedida.

\section{OUTRAS OBSERVAÇÕES}

\section{O Caso Especial do ICMS e Impostos} Indiretos

Lembrava Baleeiro que no caso do ICM era necessário fazer-se convênios entre todos os Estados-membros, segundo dispunha o art. 10 da Lei Complementar 24/75 para se conceder remissão.

Atualmente a Constituição tem a seguinte redação:

“... Art. 155. Compete aos Estados e ao Distrito Federal instituir impostos sobre... II - operações relativas à circulação de mercadorias e sobre prestaçōes de serviços de transporte interestadual e intermunicipal e de comunicaçào, ainda que as operações e as prestações se iniciem no exterior;... \& $2^{\circ} \mathrm{O}$ imposto previsto no inciso II atenderá ao seguinte:... XII - cabe à lei complementar:... g) regular a forma como, mediante deliberação dos Estados e do Distrito Federal, isenções, incentivos e beneficios fiscais serão concedidos e revogados.

Assim, se percebe que a exigência persistiria se se interpretasse a remissão como sendo um tipo de benefício fiscal, no entanto, no caso do CMS e dos demais chamados impostos indireos em geral é questionável se é possivel a concessão da remissão.

Esta dúvida surge porque nos assim chamados impostos indiretos o contribuinte de direito não é o mesmo que o contribuinte de fato, ou seja, o comerciante ou industrial apenas imbute o imposto no preco e o consumidor é quem paga o imposto, cabendo então ao comerciante rciante ou industrial o recolhimento do imposto que na realidade não foi pago por ele.

Desta maneira nos parece que conceder remissão de impostos ao contribuinte de direito, que funciona como se fosse mero agente arrecadador, é na verdade fazer uma doação pura, simples e imotivada de dinheiro público para um particur, raza pelo qual entendemos na particular, razão pelo qual entendemos não

\section{Remissão e Solidariedade}

No caso de solidariedade a remissão atinge a todos os devedores, salvo disposição de lei em contrário, pois alguns dos co-obrigados podem não satisfazer às exigências da lei concessiva da remissão.

A respeito disto diz o C.T.N.: “... Art. 125. Salvo disposição de lei em contrário, são os seguintes os efeitos da solidariedade:... II - a isenção ou remissão de crédito exonera todos os brigados, salvo se outorgada pessoalmente a um um deles, subsistindo, nesse casos, a solidarieade quanto aos demais pelo saldo;...

Note-se que o C.T.N. fala em "saldo" o que autoriza dizer que a parte do contribuinte beneficiado deve ser abatida do total, não se podendo cobrar tudo dos que não receberam o beneficio, a exemplo do que ocorre na lei civil ${ }^{23}$

\section{O Artigo 150, \& $6^{\circ}$, da Constituição Federal}

O Artigo $150, \S 6^{\circ}$, da Constituição Federal dispōe que: "Qualquer anistia ou remissão que envolva matéria tributária ou previdenciária só poderá ser concedida através de lei especifica, federal, estadual ou municipal.

Afirma Carrazza ${ }^{24}$ que a Constituição objetivou aqui não deixar dúvidas de que só o ente público com competência constitucional para tributar pode perdoar o tributo.
Observa ainda o mesmo autor que a Constituição omitiu o Distrito Federal, contudo, este evidentemente está incluído, pois se trata de um membro da Federação, não havendo motivos para exclui-lo.

Ferreira Filho, comentando este parágrafo, acrescenta que a remissão só pode ser concedida por Lei relativa ao imposto sobre o qual beneficio ocorrerá ${ }^{25}$. Talvez 0 que este autor tenha querido dizer foi que será necessário uma Lei propria para a remissão de cada tipo de tributo.

Martins e Bastos $^{26}$ ao estudarem este dispositivo constitucional confirmaram os dizeres de Carrazza acrescentado que a expressão lei es pecifica não foi muito bem escolhida pelo legislador constituinte porque para eles qualquer le que não seja complementar tratando de principios gerais é lei especifica, não importando fato de ser ou não exclusiva sobre remissão ou anistia ou conter outras matérias, no que concordamos com eles.

O que é muito interessante notar é que tal exigência se encontra disciplinada no artigo que trata das garantias do contribuinte, o que reforça nossa posição de que è garantia do contribuinte honesto que a remissão não seja dada de forma indisciplinada e imotivada.

\section{EXEMPLO CONCRETO DE COMO TEM SIDO} DADO REMISSÃO

O autor do presente estudo, como juiz de Direito, negou cumprimento à Lei Estadual Paulista $\mathrm{n}^{\mathrm{0}} 8.198 / 92^{27}$, por não atender esta lei ao disposto no C.T.N. como retro mencionado, tendo havido recurso.

Na decisão se disse que a Lei "não atendeu aos preceitos do C.T.N., pois nada fala de despacho da autoridade administrativa, que nem se encontra nos autos, e muito menos expõe em qual das cinco hipóteses previstas no art. 172 do C.T.N. embasou sua benignidade. $O$ dinheiro público não pode ser dispensado sem mais aquela, sendo inadmissivel a lei dizer simplesmente "fica dispensado o pagamento'. O contribuinte honesto tem direito público subjetivo que se atendam com rigor aos preceitos constitucionais e legais na administração do erário não podendo aceitar liberalidades imotivadas por parte do Poder Público." 28
A C. $15^{a}$ Câmara Civel do E. Tribunal de Justiça do Estado de São Paulo, em V. Acórdão da lavra do E. Desembargador Mauricio Vidigal, decidiu o mesmo feito de maneira diversa dizendo "Realmente, como sustenta o nobre magistrado houve remissão do débito, mas ela não está restrita ao procedimento previsto pelo artigo 172 do Código Tributário Nacional. Em razão de critérios de conveniência e oportunidade, nem sempre percebidos por membros do Poder Judiciário pelo simples fato de que não estão sujeitos às pressões exercidas sobre os que ocupam cargos politicos, os poderes Executivos e Legislativo têm muitas vezes concedido remissão incondicional de créditos fiscais sem as condicionar a atos fundamentados de autoridade administrativa. É que não se pode admitir que a própria lei não tenha aptidão para definir a necessidade da remissão, deixando-a a criterio da autoridade administrativa" 29

Em que pese o devido respeito e o mais elevado acatamento que merece $\mathrm{o} \mathrm{V}$. Acórdão não concordamos com ele por tudo que foi exposto no texto

Lembre-se que o Direito Administrativo, berço do Direito Tributário, tem inclusive permitido a análise do próprio mérito pelo Judiciário para se averiguar dos princípios da moralidade, razoabilidade, etc., havendo expressa previsão constitucional a este respeito no art. $37 \mathrm{da} \mathrm{CF} /$ 88.

Uma importante questão que surge è se pode o juiz, de oficio, negar cumprimento à legislação que não respeitar o Código Tributário Nacional e a resposta é positiva porque ao juiz cabe cumprir a Constituição e as leis constitucionais, como é o caso do C.T.N., não podendo o magistrado aceitar ilegalidades e jamais homologá-las, coisa que expressamente prevê o art. 129 do C.P.C. ${ }^{30}$

Lembre-se, a propósito, que os vicios de ilegalidade e lesividade das remissões que são concedidas por ai são combativeis por meio de acão popular, pois nesses casos via de regra se tratam de leis de efeitos concretos e não leis em tese ${ }^{31} 32$.

\section{CONCLUSÕES}

São várias as conclusões que chegamos nesse estudo, entre elas concluimos que se pode 
conceituar a remissão como sendo 0 ato praticado pelo credor que, por liberalidade, desobrigada o devedor de quitar a divida, tendo ela a natureza juridica de um ato legislativo unilateral.

Percebemos ainda que os requisitos de qualquer remissão são: 1. ela deve ser autorizada por lei da pessoa politica com competência constitucional para tributar; 2. deve se basear em uma das hipóteses do art. 172 do C.T.N. que é taxativo e não exemplificativo; 3 . deve ser concedida pela autoridade administrativa; e 4 . 0 despacho da autoridade deve ser fundamentado.

Averiguamos que o despacho que concede a remissão não pode ser revogado, mas apenas anulado porque se trata de ato vinculado, gerando ele sim direito adquirido se a lei foi satisfeita pelo contribuinte.

Foi esclarecido também que não è possivel, no caso dos denominados impostos indiretos, a concessão de remissão.

Vimos ainda que a remissão beneficia a todos os devedores solidários, se outorgada pessoalmente a um deles, subsistindo, nesse caso, a solidariedade quanto aos demais pelo saldo.

Infelizmente a remissão não tem sido concedida com todos os critérios aqui elencados.

0 que se tem visto è que a remissão tem sido dada como um prêmio ao mau contribuinte e como castigo àquele que honestamente tem cumprido com a lei.

Tem-se dito entre o povo que o melhor é não pagar os tributos em dia, pois mais cedo ou mais tarde estes serão total ou parcialmente perdoados, o que demonstra os nefastos efeitos da atual politica de remissōes tributárias.

Se o Estado como um todo fosse muito rico ou estivesse com dinheiro sobrando seria mais correto diminuir os impostos do que perdoar de uns e não de outros. Na verdade, no Brasil, o Estado está falido e não se justifica dar-se remissão como se tem dado.

Além de ser esta uma péssima política fiscal é ela também inconstitucional porque 0 art. 150 , II, da C. F. Dispõe: "Sem prejuizo de outras garantias asseguradas ao contribuinte, é vedado à União, aos Estados, ao Distrito Federal e aos Municipios:... II - instituir tratamento desigual entre contribuintes que se encontrem em situação equivalente,...
Bastos e Ives Gandra dizem que "sempre a anistia e a remissão representam uma injustiça em relação aos contribuintes que honraram seus compromissos, principalmente se o fizeram apesar da excessiva carga fiscal" 33

O prof. Gerd Willy ROTHMANN, no curso de pós-graduação da FADUSP, questionou esta afirmativa, achando ele que nem sempre a remissão significa uma injustiça.

Entendemos que a razão está com Bastos e Gandra. Imaginemos dois contribuintes em situações econômicas idênticas, sendo que um paga 0 tributo devido na época certa e o outro não paga. Decorre o tempo e eles entram em condicooes de merecer uma remissão que for concedida, mas só o mau pagador se beneficiará. Onde a Justiça? Evidentemente que não na remissão como aqui praticada.

A remissão pode servir como bom instrumento de politica fiscal se por meio dela se evitar a destruição ou sofrimento desnecessário do contribuinte, no entanto, nestes casos, deveria se deixar também beneficiar aqueles que honestamente cumpriram com sua obrigação fiscal no prazo legal e não só os que dão calote no fisco.

Assim espera-se que tal prática seja um dia interrompida concedendo-se remissão apenas quando o caso realmente a recomendar como medida de maior Justiça.

\section{NOTAS DE REFERÊNCIA}

1 A primeira versão deste trabalho, que foi bastante Aodícada, fol apresentada no Curso de Pós-Graduação da Faculdade de Direito da USP sendo professores os Profs. Drs. Alcides Jorge Costa e Gerd Willy Rothmann. Adotamos algumas sugestōes destes mestres no texto e lhes prestamos merecida homenagem.

Jardim, Eduardo Marcial Ferreira. "Outras formas de extinção da obrigação tributária". In "Curso de Direito Tributário". VV. AA.. Coordenador: Ives Gandra da Silva Martins. São Paulo, Saraiva/CEEU, 1982, p. $157 / 185$

Baleeiro, Aliomar. "Direito Tributário Brasileiro". $10^{\mathrm{a}}$ ed. re. e atualizada por Flávio Bauer Novelli. Rio de Janeiro, Forense, 1986. (p. 577 a 579 )

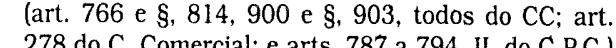
Art. 180 do C T . "A e arts. 787 a 794, II, do C.P.C.) te as infraçōes cometidas anteriormente à vigência da lei que a concede...." (grifo nosso) Denari, Zelmo, "Comentários ao Código Tributário
Nacional". IBET/Resenha Tributária, 1978, p. 180
7 Costa, Alcides Jorge. "Direito Tributário e Direito Privado". In: "Direito Tributário - Estudos em Ho Coordenador: Brandão Machado. São Paulo, Sarava, 1984, p. 221-240.

8 Carrazza, Roque Antônio. "Curso de Direito Consttucional Tributário". $4^{a}$ edição. São Paulo, Malheros, 1993, p. 380.

9 As dimensōes deste trabalho, por ser um artigo de revista, não permitem grande divagação pelo Direito Comparado, por isso, fazemos esta brevissima nota para que este importante aspecto não passe totalmente em branco.

0 Código Tributário da Alemanha (AO/77) assim dispoe sobre 0 assunto. .... \& 227 Remissa.o.(1) As autoridades fiscais podem remitir pretensô decorrentes da relaçáo de debito de imposto, tota ou parcialmente, quando a sua cobrança violar a eqüidade, conforme as circunstâncias do caso concreto; nas mesmas condiçoes, podem ser restituídas ou compensadas as importancias pagas. (2) Os poderes previstos no inciso 1 cabem a autoridade fiscal superior da pessoa juridica que administra 0 mposto ou as reparticas jiscas por ela indicadas.

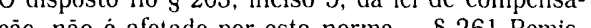
são. Pretensōes originárias da relaço de débito de imposto poderão ser objeto de remissão, se for constatado que a cobranca não será bem sucedida ou se as respectivas custas forem desproporcionais em relação à importância a ser cobrada." (Alemanha. Leis, Decretos, etc. "Abrgabenordnung (AO - 1977)". Novo Código Tributário. Tradução de Alfred J. Schmid e outros. Rio de Janeiro/São Paulo, Forense/ IBDT-USP, 1978]

Fonrouge, citando Tesoro, Berliri, Giannini, ingrasso e Pughiese, afirma que na Itália o Estado esta absolutamente proibido de conceder remissáo. O mesno mestre, falando da Argentina, diz que la è penmido, mas de forma limitada, sendo concedida pelo Diretor Geral da "Dirección Impositiva" com cacionais devidamente justificadas, tais como inundaçōes, terremotos ou grandes catástrofes, aplicando-se somente a alguns impostos e não havendo lá anistia de infrações tributárias. (Fonrouge, Carlos M. Giuliani. "Derecho Financiero". $2^{\mathrm{a}}$ edición, Buenos Aires, Depalma, 1970, vol. I, p. 562.

10 "Artigo 172. A lei pode autorizar a autoridade admnistrativa a cli pode autorizar a autoridade administrativa a conceder, por despacho fundamentado, dendo I à situacáo do credito tributario, atenvo; II 1 - a a situaçáo econonica do sujeito passi-

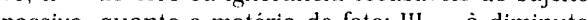
importân racōes de eqüidade, em relaço com as caracteristicas pessoais ou materiais do caso: $\mathrm{V}-\mathrm{a}$ condichos peculiares a determinada região do território da entidade tributante...
11 França, R. Limongi. "Hermenêutica Jurídica". $2^{\mathrm{a}}$ edição. São Paulo, Saraiva, 1988, p. 49.

2 Nogueira, Ruy Barbosa. "Curso de Direito Tributário". 8ª edição. São Paulo, Saraiva, 1987, p. 107. Nogueira, Ruy Barbosa. "Direilo

Paulo, Bushatsky, 1964, p. 51. no Direito Tributário Brasileiro". (In: Revista de Direito Administrativo 130/13-39) p. 23/24,

15 Bonilha, Paulo Celso Bergstrom. "Da remissão ou cancelamento de débitos fiscais de diminuto valor". Repertório IOB de Jurisprudência, $1^{\text {a }}$ quinzena de julho de 1988, n 13/88, p. 191.

6 Trouxe Bonilha decisoes do extinto Tribunal Federal de Recursos sobre esta questao da restituiçáo onde este entendeu que a quantia consignada em juizo e alcançavel pela remissão, o mesmo não ocorrendo quando já houvesse sido realizada arrematação do bem penhorado.

Na hipótese da consignação disse o mesmo Tribunal que a remissão não ocorrera porque "o depósito em juizo não significa ainda pagamento que só se verifica com sua conversão em renda da União. devera ser restituida ao executado, sem que baja porera ser restituida ao executado, sem que haja, $7.450 / 85^{\prime \prime}$ (A aravo de Instrumento $\mathrm{n}^{\circ} 52.032 \mathrm{pu}$ blicado no Diário Oficial da Unĩ̃o de 28 de abril de 1988, citado por Bonilha, p. 190) Quanto à arrematação entendeu o E. Tribunal
que "Eletuado o leilão, com a conseqüente arrematação do bem penhorado, este ato não se desconstitui pela superveniência de lei concedendo remissão. Irrelevância de, quando de sua edição, haver em curso embargos à arremataçāo. A transmissão de propriedade já se verificara, embora pudesse desfazer-se 0 ato com a eventual procedência dos embargos. Julgados improcedentes, mantém-se integra a alienação ja anteriormente ocorrida" (Agravo de Instrumento $\mathrm{n}^{\circ} 54.039$, publicado no $\mathrm{D}$. O. U. de 28 de abril de 1988, p. 9.737, citado por Bonilha, p. 190).

17 Moreira, João Baptista. obra citada

Silveira, Alipio. "Hermeneutica no Direito Brasileiro". São Paulo, RT, 1968, dois volumes, p. 370

19 Baleeiro, Aliomar, obra citada, p. 439

Interessante, notar que neste caso, no Direito alemão, um dos mais perfeitos do mundo em termos tributärios, há expressa previsão legal de restituiçào do tributo a quem ja o pagou, o que nos parece mais justo do que o que se laz aqui, confira-se: "... § mitir pretensóes decrentes da relaca de debito de imposto, tola ou parcialmente, quando a sua cobranca vilar a equidade, conforme as circunstâncias do caso concreto: nas mesmas condicões, podem ser restituidas ou compensadas as importâncias pagas." (grifo nosso) (AO/77) 
21 Fanucchi, Fábio. "Curso de Direito Tributário Brasileiro". Vol. I e II. $4^{a}$ edição, São Paulo, Editora Resenha Tributária, 1986, p. 341/342

22 Jardim, Eduardo Marcial Ferreira. Obra citada. p. 168,

23 Código Civil: "art. 1.055. A remissão concedida um dos co-devedores extingue a divida na parte ele correspondente; de modo que, ainda reservando o credor a solidariedade contra os outros, já lhes não pode cobrar o débito sem dedução da parte remitida.

24 Carrazza, Roque Antônio. Obra citada, p. 381

Ferreira Filho, Manoel Gonçalves. Comentários a Constituição Brasileira de 1988. São Paulo, Saraiva, 1994, vol. 3, p. 107

26 Bastos, Celso Ribeiro e Martins, Ives Gandra. "Comentários à Constituição do Brasil". São Paulo, Sa ralva, 1990, vol. 6, tomo 1, pp. $211 / 214$.

A dicão de micrompresa enquanto que 0 a contrata de porcentagen do ICMS e o que nos interess é 0 artigo $3^{\circ}$ que singelamente diz o seguinte: "Fica dispensado o pasamento do Imposto sobre a Circulação de Mercadorias e sobre Prestacōes de Servicos de Transporte Interestadual e Intermunicipal de Comunicação - ICMS em relação a operaçós ocorridas até a data da publicação desta Lei, com: - alimentação fornecida em restaurantes, bares. cafés e estabelecimentos similares; II - program para computador ("software"), personalizado ou nầo. Parágrafo única. 0 disposto neste artigo não se aplica ao fornecimento e à distribuição de bebidas nem autoriza a restituição de tributos ja recolhi-

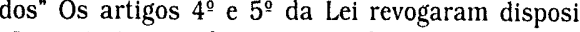
ços anteriores e dispuseram sobre a vigencia imediata da Lei..
Perceba-se a intenção, comum neste tipo de lei, de premiar somente o mau pagador pois aquele que honrou sua obrigacão civica para com o fisco não terá restituição do tributo já recolhido.

28 Processo $\mathrm{n}^{\circ}$ 561/91 da Vara do Anexo Fiscal da Comarca de Sāo Vicente, SP.

29 Agravo de Instrumento $\mathrm{n}^{\mathrm{0}}$ 246.145-2/3 - MV 911 - referente ao processo mencionado na nota anterior

"Convencendo-se, pelas circunstâncias da causa, de que 0 autor e 0 reu se serviram do processo para... conseguir fim proibido por lei, o juiz proferira senlença que obste aos objetluos das partes" (art. C.P.C.

31 Conforme Lei $4.717 / 65$, art. $1^{\circ}$ e RJTJESP 103/ 169

A título de curiosidade trazemos à colação o artigo publicado no Jornal "O Estado de São Paulo" no "Acordos prejudicaram contrucáo de casom", eschAcordos prejudicaram con

to quando diz que "A rede Mcdonte e dela que ele fala anistia fiscal concedida a 300 mil devedores do ICMS entre bares, restaurantes e distribuidores de software." Disse ainda a reportagem que "O governo... deixou de construir cerca de 8 mil casas populares perdoando a divida... "e parcelando outra, somando os casos R $\$ 30$ milhöes". Acrescentou a reporter que o governo "... construiu $88 \mathrm{mil}$ casas populares em cinco anos.. poderia ter feito mais se não perdoasse divida de quem tem dinheiro para pagar segundo o que the disse o presidente do $\mathrm{CDHU}$

Bastos, Celso Ribeiro e Martins, Ives Gandra. Obra citada, p. 212

\section{As Contribuições Parafiscais no Direito Brasileiro}

FranZ AUGUST GERNOT LIPPERT

Professor Adjunto da Faculdade de Direito da UFRGS

\section{PLANO DE TRABALHO}

1. Introduçāo: 1.1. Razōes Sociais; 1.2. Razōes Politicas; 1.3. Razōes Orçamentárias; 2. Normas Juridicas Atinen tes a Contribuicōes em Geral: 2.1. Normas Constitucionais; 2.2. Leis Complementares; 2.3. Leis Ordinärias; $\mathbf{3}$. A Natureza Juridica das Contribuicōes Especiais: 3.1. Fato Gerador: 3.1.1. Sujeito Ativo; 3.1.2. Sujeito Passivo; 3.2 Natureza Juridica; 3.3. Situaçāo Atual: 3.4.1. Criação da Contribuição; 3.4.2. Inclusão no Orçamento; 3.4.3. Controle Pelo Tribunal de Contas

\section{PREÂMBULO}

"A parafiscalidade é uma modalidade nova de finanças públicas, embora com antecedentes históricos, própria do Estado intervencionista, visando instituir e utilizar receitas de aplicação especifica, fora do orçamento estatal, à conta de órgãos com finalidades econômicas, de organização profissional, de assistência e previdência sociais, arrecadadas diretamente pelas entidades aplicadoras ou por meios indiretos, inclusive pelas próprias repartições fiscais do Estado.

Sylvio Santos Faria. Aspectos da Parafiscalidade. Livraria Progresso Editora, Salvador, 1.ed., p. 103, 1955.

\section{O SURGIMENTO DAS CONTRIBUIÇÕES ESPECIAIS OU PARAFISCAIS}

Investigando as causas do surgimento das Contribuicões Parafiscais, constata-se serem estas as mais diversas, sendo-lhes, entretanto, comum a necessidade do Estado de obter recursos para o atendimento de suas incumbên-
cias, decorrentes de determinados fatos politicias, decorrentes de determinados fatos politicos, sociais e econ

Caracterizou-se este século: na área social pela tenaz luta da humanidade, objetivando conquistar uma qualidade de vida melhor e, na área politica, por duas guerras mundiais, as quais, se, de um lado, provocaram um progresso enorme em determinadas áreas, especialmente nas areas da ciencias exatas, acarretaram enormes perdas humanas e econômicas, nảo apenas dos paises vencidos, mas também dos paises vencedoręs, com exceção dos Estados Unidos, quanto às perdas materiais.
Tais fatos exigiram do Poder Público, quase a nivel mundial, quanto à obtençảo, adminis tração e aplicação de recursos, ações imediatas, incompativeis com as normas tradicionais da previsão, elaboração e execução orçamentária.

Sendo impossivel, de um lado, atender às inúmeras necessidades sociais, e constatandose, de outro lado, a existência de interesses grupais, a respeito, passou o Poder Público a promover a criação de novos órgãos, relacionados diretamente com aqueles grupos para, aumentar sua eficiência politica e administrativa na solução destes problemas (grupais).

Sendo imprescindivel para o adequado funcionamento dos novos órgãos, também denominados da administração pública indireta, atri buir-lhes os meios financeiros necessários, foram então criadas novas exacões.

Convencionou-se chamá-las de "contribuiçōes parafiscais", "contribuiçōes especiais" ou simplesmente "contribuiçōes", "Sonderabgaben"1 